\title{
Quantificação de cianeto total nas etapas de processamento das farinhas de mandioca dos grupos seca e d'água
}

\author{
Renan Campos CHISTÉ ${ }^{1}$, Kelly de Oliveira COHEN², Erla de Assunção MATHIAS ${ }^{3}$, Suzy Sarzi OLIVEIRA ${ }^{4}$ \\ RESUMO \\ O objetivo deste trabalho foi quantificar a concentração de cianeto total durante as etapas de produção da farinha de mandioca \\ dos grupos seca e d'água. Em relação à farinha seca, a concentração de cianeto total na raiz de mandioca diminuiu de 160 $\pm 11,8$ \\ $\mathrm{mg} \mathrm{HCN} / \mathrm{kg}$ para $149 \pm 12,3 \mathrm{mg} \mathrm{HCN} / \mathrm{kg}$ após a trituração, $68 \pm 2,5 \mathrm{mg} \mathrm{HCN} / \mathrm{kg}$ após a prensagem e chegando a $5 \pm 0,2 \mathrm{mg}$ \\ $\mathrm{HCN} / \mathrm{kg}$ no produto final, após o processo de torração. Na produção da farinha d'água, a raiz de mandioca apresentava teor \\ de cianeto total de $321 \pm 21,6 \mathrm{mg} \mathrm{HCN} / \mathrm{kg}$ e durante o processo de fermentaçáo da raiz, o teor de cianeto total nas primeiras \\ 24 horas de fermentação era de $297 \pm 2,7 \mathrm{mg} \mathrm{HCN} / \mathrm{kg}$ chegando a $64 \pm 2,3 \mathrm{mg} \mathrm{HCN} / \mathrm{kg}$ após 96 horas em repouso no tanque.

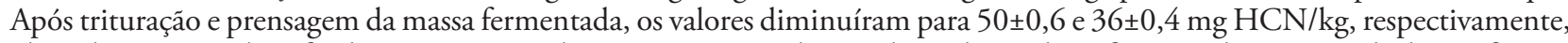 \\ obtendo-se no produto final a concentração de $9 \pm 0,1 \mathrm{mg} \mathrm{HCN} / \mathrm{kg}$, sendo evidenciado a eficiência do processo de destoxificação \\ em ambos os processamentos.
}

PALAVRAS-CHAVE: Manihot esculenta Crantz, destoxificação, ácido cianídrico, linamarina.

\section{Total cyanide quantification in processing stages of cassava flour from dry and water groups}

\section{ABSTRACT}

The aim of this work was to quantify the total cyanide concentration during the production stages of cassava flour from dry and water groups. In relation to dry flour, the total cyanide concentration in the cassava root reduced from $160 \pm 11.8 \mathrm{mg}$ $\mathrm{HCN} / \mathrm{kg}$ to $149 \pm 12.3 \mathrm{mg} \mathrm{HCN} / \mathrm{kg}$ after grinding, $68 \pm 2.5 \mathrm{mg} \mathrm{HCN} / \mathrm{kg}$ after pressing and $5 \pm 0.2 \mathrm{mg} \mathrm{HCN} / \mathrm{kg}$ was obtained in the final product after the roasting process. For the water flour production, the cassava root showed $321 \pm 21.6 \mathrm{mg} H \mathrm{HCN} / \mathrm{kg}$ total cyanide content, and during the fermentation process, the total cyanide content for the first 24-hour fermentation was from $297 \pm 2.7 \mathrm{mg} \mathrm{HCN} / \mathrm{kg}$ reaching $64 \pm 2.3 \mathrm{mg} \mathrm{HCN} / \mathrm{kg}$ after resting in a pool for 96 hours. After grinding and pressing-the fermented roots, the values lowered to $50 \pm 0.6$ and $36 \pm 0.4 \mathrm{mg} \mathrm{HCN} / \mathrm{kg}$, respectively. A concentration of $9 \pm 0.1 \mathrm{mg} \mathrm{HCN} / \mathrm{kg}$ was obtained in the final product, evidencing the detoxification process efficiency in both processings.

KEYWORDS: Manihot esculenta Crantz, detoxication, cyanidric acid, linamarin.

\footnotetext{
1 Universidade Estadual de Campinas. E-mail: renanchiste@gmail.com

2 Empresa Brasileira de Pesquisa Agropecuária. Cerrados. E-mail: kelly.cohen@cpac.embrapa.br

3 Universidade Federal do Pará. E-mail: erlamorena@yahoo.com.br

${ }^{4}$ Empresa Brasileira de Pesquisa Agropecuária. Amazônia Oriental. E-mail: suzy@cpatu.embrapa.br
} 


\section{INTRODUÇÃO}

O estado do Pará, na condição de maior produtor brasileiro de mandioca, participa com aproximadamente $20 \%$ da produção nacional (IBGE, 2007). A produção de farinha de mesa, a principal forma de aproveitamento das raízes, representa atividade de importância social porque grande contingente da população rural participa desta produção, além de representar uma contribuição econômica significativa para os municípios paraenses (Cardoso et al., 2001). Trata-se de produto heterogêneo quanto aos parâmetros de qualidade, ao ser comparada a produçáo entre produtores, pois a fabricação muitas vezes é dada de forma ainda artesanal por pequenos agricultores para uso próprio, cada um seguindo processo próprio. Numa mesma propriedade é raro ocorrer uniformidade em fabricaçóes sucessivas.

De acordo com a Portaria no 554, de 30.08.1995 do Ministério da Agricultura, Pecuária e Abastecimento (MAPA) (Brasil, 1995), a farinha de mandioca seca é o produto das raízes de mandioca sadias, devidamente limpas, descascadas, trituradas, prensadas, desmembradas, secas à temperatura moderada ou alta e novamente peneirada ou não, podendo ser beneficiada. Já a farinha de mandioca d'água segue o mesmo processamento, no entanto, as raízes devidamente limpas são expostas ao processo de maceração (fermentação) sendo deixadas em repouso por geralmente 4 dias, resultando no amolecimento das raízes de mandioca durante o processo, conforme relata Campbell-Platt (1987). Este processo é realizado em água parada (tanques) ou água corrente (igarapés) a qual confere às raízes características sensoriais peculiares (Sarmiento, 1993).

A mandioca pertence ao grupo de plantas cianogênicas por apresentar glicosídeos cianogênicos em sua composição. De acordo com Cagnon et al. (2002), tais glicosídeos, conhecidos como linamarina e lotaustralina (proporção de 93:7 no tubérculo), após ruptura da estrutura celular da raiz, entram em contato com as enzimas presentes (linamarase) degradando estes compostos, liberando ácido cianídrico ( $\mathrm{HCN})$, que é o princípio tóxico da mandioca e cuja ingestão ou mesmo inalação, representa sério perigo à saúde, podendo ocorrer casos extremos de envenenamento. Segundo Mattos et al. (2002), a farinha pode ser produzida com mandiocas mansas (menos de $50 \mathrm{mg}$ de $\mathrm{HCN} / \mathrm{kg}$ de raiz fresca sem casca, conhecida popularmente como macaxeira ou aipim) ou bravas (acima de $100 \mathrm{mg}$ de $\mathrm{HCN} / \mathrm{kg}$ de raiz fresca sem casca).

Segundo Cagnon et al. (2002), a liberação do cianeto da mandioca se dá no momento em que o tecido vegetal é dilacerado, então a linamarina é hidrolisada enzimaticamente por $\beta$-glicosidase (linamarase), a qual é separada do glicosídeo no tecido intacto, por ser localizada em lugar distinto da célula. A clivagem produz glicose e $\boldsymbol{\alpha}$-hidroxinitrilas. Esta última, quando catalisada por uma hidroxinitrila-liase, transforma-se espontaneamente em HCN e nas cetonas correspondentes. Esse processo é chamado de cianogênesis.

Borges et al. (2002) avaliaram 26 variedades de mandioca aos 8,10 e 12 meses após o plantio quanto ao teor de cianeto total com o objetivo de identificar novas variedades para consumo humano, na forma de raízes frescas. Concluíram que aproximadamente, $81 \%$ das variedades continham teores de cianeto dentro dos limites aceitáveis (inferior a $100 \mathrm{mg} / \mathrm{kg}$ de polpa crua) para consumo na forma de raízes frescas.

Unung et al. (2006) citam que no processamento tradicional das raízes de mandioca, os compostos cianogênicos diminuem substancialmente o teor, no entanto, os níveis continuam acima do reconhecidamente seguro. Cereda (2003) explica que casos significativos de envenenamento por cianeto são restritos às regiôes onde existe deficiência nutritiva e a mandioca representa grande parte da dieta alimentar. Logo, é preciso conhecer bem o mecanismo de liberaçấo do cianeto para melhor compreender as informaçóes sobre destoxificação, intoxicaçóes agudas e doenças ligadas ao consumo contínuo da mandioca e seus subprodutos, ainda contendo linamarina residual.

Após estudos da determinaçáo do potencial de intoxicação em ratos, de linamarina extraída de mandioca, feita por Cereda \& Lopes (2003), os autores chegaram à conclusão de que a $\mathrm{DL}_{50}$ (dose letal para $50 \%$ de ocorrência) oral de linamarina extraída foi $325 \pm 1,5 \mathrm{mg} / \mathrm{kg} /$ peso, correspondendo a $35 \mathrm{mg}$ de $\mathrm{HCN} / \mathrm{kg}$ peso. $\mathrm{A} \mathrm{DL}_{50}$ aceita pela OMS é de $10 \mathrm{mg} / \mathrm{kg}$ de peso. Segundo Cereda (2003), a única forma tóxica da linamarina é a de cianeto livre $\left(\mathrm{CN}^{-}\right)$, ou de seu ácido $(\mathrm{HCN})$. Abaixo da dose letal existe um mecanismo de destoxificação, na qual o cianeto é transformado em tiocianato, em presença da enzima rodanase, e cisteína, um aminoácido doador de enxofre. $\mathrm{O}$ tiocianato formado não é tóxico e é eliminado pela urina.

Sendo a farinha de mandioca (seca ou d'água) a principal fonte de carboidrato para uma significativa parcela da população de menor poder econômico no estado do Pará, com consumo per capita de $34 \mathrm{~kg}$ na regiáo metropolitana de Belém (CARDOSO et al., 2001), o objetivo deste estudo é quantificar o teor de cianeto total nas etapas de processamento da farinha de mandioca dos grupos seca e d'água e avaliar a eficiência da destoxificaçáo do cianeto, desde a raiz até o produto final.

\section{MATERIAL E MÉTODOS}

\section{MATÉRIA-PRIMA E PRODUÇÃO DE FARINHA DOS GRUPOS SECA E D'ÁGUA}

Para cada tipo de farinha produzida foram utilizados 5 kg de raízes de mandioca brava da variedade Olho Vermelho, com 16 meses e 17 meses, colhidas no mês de janeiro de 2006 
para o processamento da farinha seca e fevereiro de 2006 para o processamento da farinha d'água, sendo as raízes oriundas do Banco de Germoplasma da Embrapa Amazônia Oriental, Belém-PA, Brasil.

A produção das farinhas de ambos os grupos foi realizada em escala laboratorial, artesanalmente, da maneira como é processado nas casas de farinha do interior do estado do Pará (Figura 1).

\section{QUANTIFICAÇÃO DO CIANETO TOTAL}

A quantificação foi realizada em quatro pontos do processamento para farinha seca, denominados: RD (raíz descascada), RT (raiz triturada), MP (massa prensada) e FS (farinha de mandioca do grupo seca); e oito pontos do processamento para a farinha d'água, assim denominados: RDS (raiz descascada), R24 (raiz após 24 horas de maceração), R48 (raiz após 48 horas de maceração), R72 (raiz após 72 horas de maceração), R96 (raiz após 96 horas de maceração), RMT (raiz macerada triturada), RMP (raiz macerada prensada) e FD (farinha de mandioca do grupo d'água). Após cada etapa de processamento da mandioca, amostras escolhidas aleatoriamente, em diferentes pontos, foram retiradas e analisadas em quadruplicata para quantificaçáo do cianeto total por espectrofotometria, utilizando a metodologia descrita por Cooke (1978) e, posteriormente adaptada por Essers et al. (1993), com algumas modificaçóes. Nesta metodologia, baseada na reação de König, o cianeto $\left(\mathrm{CN}^{-}\right)$é oxidado à haleto de cianogênio cloroamina $\mathrm{T}$ ou $\mathrm{N}$-clorosuccinimida. Este composto reage com ácido isonicotínico para produzir um dialdeído, que acopla com aminas ou compostos com o grupamento metileno ativo, como ácido dimetilbarbitúrico, para formar um complexo colorido, e posterior leitura em espectrofotômetro a $605 \mathrm{~nm}$.

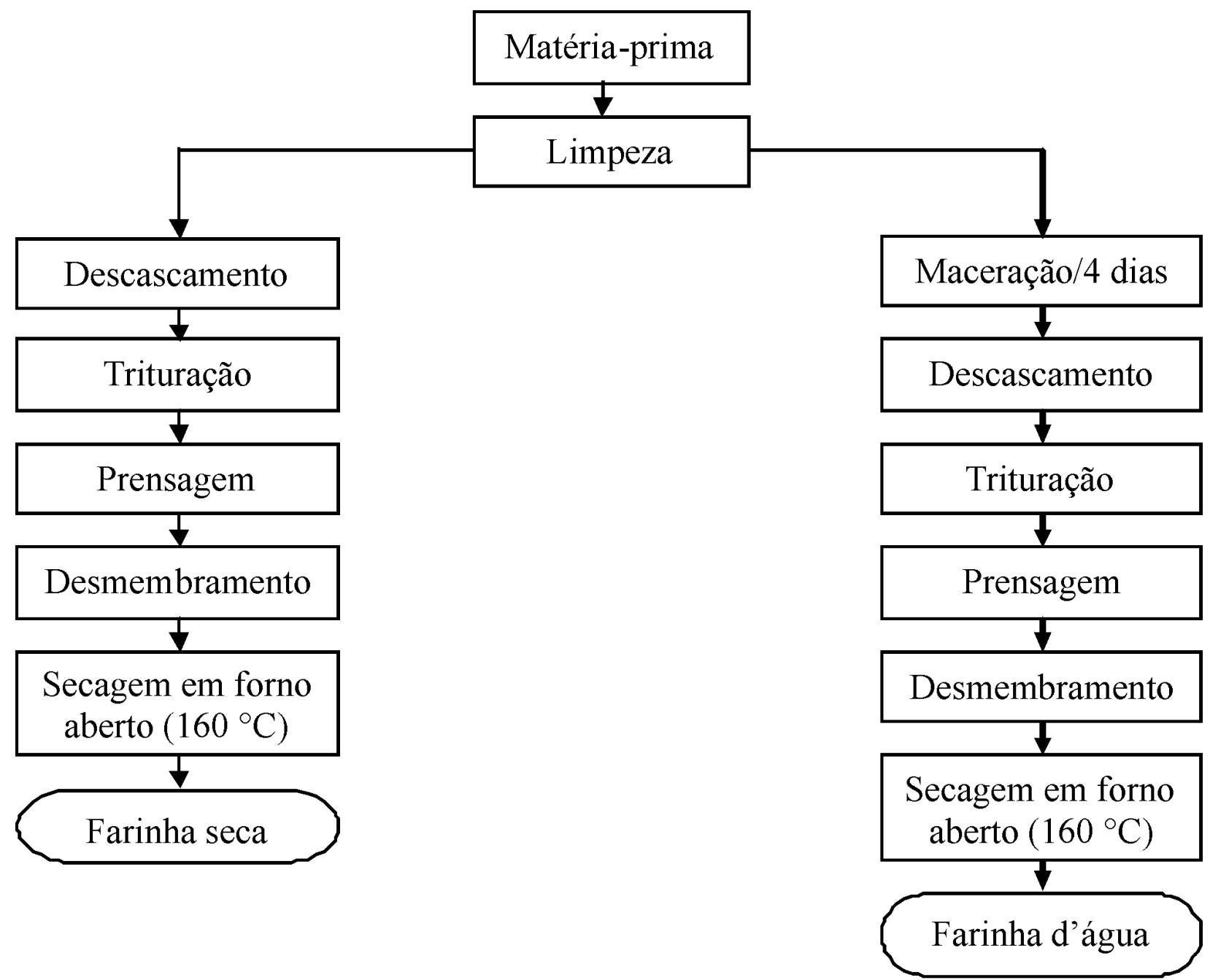

Figura 1 - Fluxograma do processo de fabricação das farinhas de mandioca dos grupos seca e d'água. 
Para extraçáo dos compostos cianogênicos, foram pesados $10 \mathrm{~g}$ de raízes (durante as etapas em ambos os processos) e $30 \mathrm{~g}$ de farinha de mandioca, adicionado $60 \mathrm{~mL}$ de soluçáo alcoólica de ácido fosfórico 0,1 M (solução extratora) e triturados em processador de alimentos por 3 minutos. O conteúdo do processador foi transferido quantitativamente para tubos de vidro e centrifugados a 3000RPM/10 min, sendo o extrato sobrenadante, contendo os glicosídeos cianogênicos, retirado e transferido para baláo volumétrico de $100 \mathrm{~mL}$.

Em seguida, $0,1 \mathrm{~mL}$ do extrato ácido obtido foi adicionado em tubo de ensaio contendo $0,4 \mathrm{~mL}$ de tampão $\mathrm{pH} 7,0$, sendo adicionado então a enzima linamarase e o tubo submetido a banho-maria por $15 \mathrm{~min}$ a $30^{\circ} \mathrm{C}$, promovendo a lise dos glicosídeos cianogênicos. Após esta etapa, foi adicionado 0,6 $\mathrm{mL}$ de solução $\mathrm{NaOH} 0,2 \mathrm{M}$ e deixado por 5 minutos em repouso à temperatura ambiente $\left(25 \pm 1^{\circ} \mathrm{C}\right)$, decompondo a cianoidrina rapidamente para cianeto em solução alcalina. Em seguida, foi adicionado 2,8 $\mathrm{mL}$ de tampão $\mathrm{pH}$ 6,0 e 0,1 $\mathrm{mL}$ de cloroamina $\mathrm{T}$, agitando o tubo para homogeneizar o conteúdo e depois submetido a banho de gelo por 5 minutos. Finalmente foram adicionados $0,6 \mathrm{~mL}$ do reagente de cor no tubo de ensaio, sendo agitado posteriormente, e deixado em repouso por 10 minutos à temperatura ambiente. Depois de passado o tempo da reaçáo, o complexo colorido contido no tubo de ensaio, de cor azul, foi lido em espectrofotômetro a $605 \mathrm{~nm}$. A curva de calibração foi construída a partir de 11 pontos, com concentração variando de 0,013 a 2,708 $\mu \mathrm{g}$ HCN. $0,1 \mathrm{~mL}^{-1}$.

\section{ANÁLISE ESTATÍSTICA}

Os resultados médios obtidos durante o estudo (média \pm desvio padráo) foram analisados com o auxílio do programa Statistica versão 5.5 , empregando as análises de variância (ANOVA) e Teste de Tukey $(\mathrm{p}<0,05)$.

\section{RESULTADOS E DISCUSSÃO}

As possíveis variaçóes dos teores iniciais de cianeto no tubérculo estão relacionadas com as características intrínsecas da matéria-prima, como a variedade, teor de nitrogênio no solo, clima e idade da planta.

É importante ressaltar que mandiocas com elevados teores de linamarina potencialmente hidrolisáveis a cianeto na raiz, podem apresentar elevado valor residual na elaboração da farinha de mandioca caso a destoxificação (degradaçáo do $\mathrm{HCN}$ ) não seja eficaz durante o processamento.

A Figura 2 exibe a redução do teor de cianeto total no decorrer da produção da farinha de mandioca do grupo seca. A raiz de mandioca fresca e descascada (RD) apresenta teor inicial de $160 \pm 11,8 \mathrm{mg} \mathrm{HCN} / \mathrm{kg}$, confirmando a caracterização do tubérculo como brava ou venenosa, por possuir teor de cianeto superior a $100 \mathrm{mg} \mathrm{HCN} / \mathrm{Kg}$. Após a trituraçấo da raiz, o teor de ácido cianídrico diminuiu para $149 \pm 12,3 \mathrm{mg}$ $\mathrm{HCN} / \mathrm{kg}$, no entanto não foi verificada diferença estatística significativa $(\mathrm{p}<0,05)$ entre a amostra descascada e a triturada. De acordo com Cagnon et al. (2002), após a dilaceração do tecido vegetal a linamarase ( $\beta$-glicosidase EC3.2.1.21) entra em contato com o substrato linamarina e dá início ao processo de cianogênese.

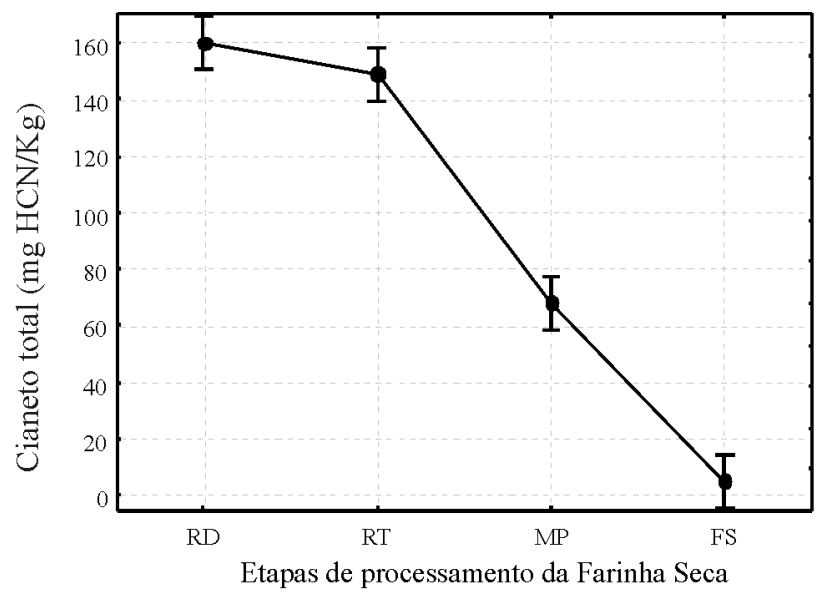

Figura 2 - Cianeto total durante 0 processamento da farinha de mandioca do grupo seca.

Sendo solúvel em água, a maior parte dos glicosídeos capazes de gerar HCN, como a linamarina e a lotaustralina, são removidos durante a etapa de prensagem, na qual a massa triturada é colocada em prensas para remoçáo da manipueira, líquido residual utilizado como matéria-prima para produção do tucupi (Chisté et al., 2007). Conforme mostrado na Figura 2, após a prensagem o teor de cianeto total diminuiu significativamente $(\mathrm{p}<0,05)$ na massa $(\mathrm{MP})$, passando para $68 \pm 2,5 \mathrm{mg} \mathrm{HCN} / \mathrm{kg}$. Finalmente, após o processo de torraçáo da massa prensada para obtenção da farinha de mandioca do grupo seca (FS), o teor de cianeto total também decaiu significativamente $(p<0,05)$ para $5 \pm 0,2 \mathrm{mg} \mathrm{HCN} /$ $\mathrm{kg}$ em decorrência da volatilização do composto através da exposição à elevada temperatura do forno. Chisté \& Cohen (2008) ao quantificarem o teor de cianeto total em amostras de farinhas de mandioca do grupo seca comercializadas nas principais feiras e supermercados da cidade de Belém-PA, encontraram valores considerados de baixa concentração de cianeto, variando de 7,68 a 20,57 mg HCN/kg, e Muzanila et al. (2000) encontraram valor de $6,8 \mathrm{mg} \mathrm{HCN} / \mathrm{kg}$ de farinha seca produzida na regiáo da Tanzânia.

Com relaçáo ao processamento da farinha de mandioca do grupo d'água, a reduçáo no teor de cianeto total é demonstrada através da Figura 3. Tratando-se de mandioca brava, o teor de cianeto na raiz descascada (RDS) inicialmente foi de $321 \pm 21,6 \mathrm{mg} \mathrm{HCN} / \mathrm{kg}$, exibindo maior teor de cianeto total com relaçáo à mesma variedade utilizada no mês anterior para 
processamento da farinha seca. Em seguida, as raízes foram imersas em tanque contendo água (até cobrir totalmente) para dar início à etapa de maceração (fermentação) do tubérculo, responsável pelas características sensoriais peculiares da farinha d'água.

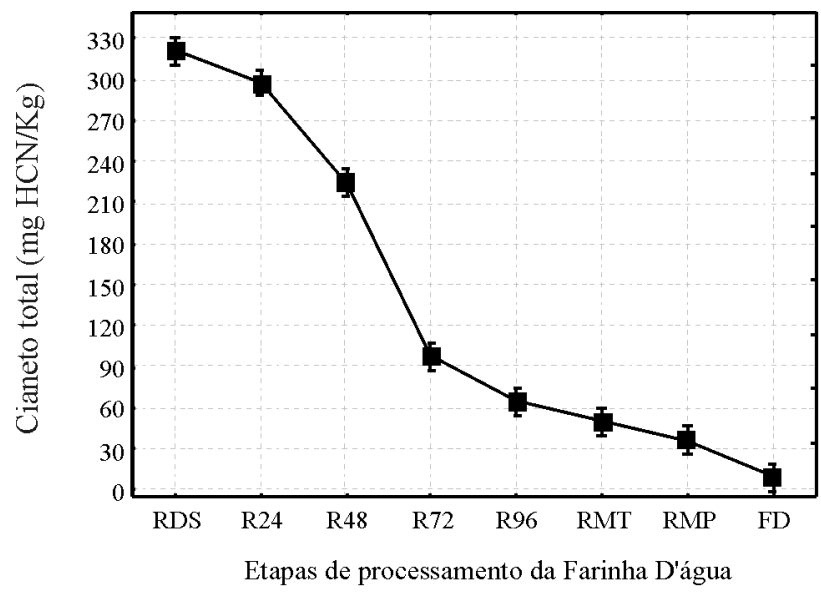

Figura 3 - Cianeto total durante o processamento da farinha de mandioca do grupo d'água.

Após 24, 48, 72 e 96 horas de maceração (R24, R48, R72 e R96), o teor de cianeto total diminuiu para $297 \pm 2,7,224 \pm 6,1$, $97 \pm 4,6$ e $64 \pm 2,3 \mathrm{mg} \mathrm{HCN} / \mathrm{kg}$, respectivamente, diferenciandose estatisticamente $(\mathrm{p}<0,05)$ uma das outras durante o período de fermentaçáo da raiz. A diminuiçấo dos teores de ácido cianídrico durante o período de fermentaçáo evidencia a eficiência do processo de maceração na destoxificação da raiz. Onabowale (1992) cita que o ácido cianídrico da mandioca pode ser destoxificado por fermentação, hidrólise ácida ou ambos, sendo que fermentação sozinha pode diminuir o teor de $\mathrm{HCN}$ em até $87,8 \%$. No presente estudo, o processo de maceração reduziu em $80 \%$. Segundo Cereda (2003), na sua origem a fermentação das raízes tinha por objetivo o amolecimento da mandioca para facilitar o processo de ralação nos raladores primitivos disponíveis. No entanto, ao mesmo tempo em que ficam mais macias, podendo ser desintegradas em pilóes, por exemplo, a linamarina solúvel é carreada para os rios (ou água parada).

Após o processo fermentativo, a raiz (R96) foi então triturada (RMT) e o teor de cianeto total passou a $50 \pm 0,6$ $\mathrm{mg} \mathrm{HCN} / \mathrm{kg}$, não havendo diferença estatística significativa $(\mathrm{p}<0,05)$ entre R96 e RMT. Em seguida, a RMT foi prensada (RMP) para retirada da manipueira, reduzindo o teor para $36 \pm 0,4 \mathrm{mg} \mathrm{HCN} / \mathrm{kg}$, uma vez que a linamarina e o $\mathrm{HCN}$ são carreados devido à prensagem e a solubilidade em água. Após prensada, a massa foi levada ao forno com elevada temperatura $\left(160 \pm 22^{\circ} \mathrm{C}\right)$, obtendo o produto final (FD) com teor de cianeto total de $9 \pm 0,1 \mathrm{mg} / \mathrm{HCN} / \mathrm{kg}$, valor este diferente estatisticamente $(\mathrm{p}<0,05)$ dos anteriores. Chisté \&
Cohen (2008) ao quantificarem o teor de cianeto total em farinhas de mandioca do grupo d'água comercializadas nas principais feiras e supermercados da cidade de Belém-PA, encontraram valores variando de 3,57 a 12,36 mg HCN/ $\mathrm{kg}$, e Muzanila et al. (2000) encontraram valor de $5,84 \mathrm{mg}$ $\mathrm{HCN} / \mathrm{kg}$ em farinha fermentada em água produzida na região da Tanzânia, sendo os teores em ambos os casos próximos ao encontrado no presente estudo.

Com base na diminuição dos teores de cianeto total obtidos após ambos os processos, verifica-se a eficiência da destoxificação durante a produção das farinhas, sendo, portanto, produtos seguros quanto a este aspecto. $\mathrm{O}$ processo, de maneira geral, que consiste na trituração da raiz, prensagem e secagem em elevadas temperaturas (torrefação), é efetivo sob o aspecto da eliminaçáo do cianeto, pois de acordo com Cereda (2003), ao triturar a raíz coloca-se em contato enzima e substrato nas melhores condiçôes de reação, $\mathrm{pH}$ entre 5,5 e 6,0 (pH natural da raiz) e temperatura ambiente. Depois de proporcionar as condiçôes ótimas para a hidrólise, a prensagem carreia a linamarina que possa ter restado íntegra e a acetona cianoidrina, ambas solúveis em água. Por fim o cianeto livre, na forma de HCN é eliminado pelo aquecimento do produto úmido, em forno aberto.

\section{CONCLUSÃO}

O processamento da farinha de mandioca do grupo seca e d'água trata-se de um processo efetivo na destoxificação do cianeto na mandioca, uma vez que a concentração de HCN durante as etapas diminuiu drasticamente (aproximadamente 97\%) em ambos os processos, garantindo a qualidade alimentar do produto final, sem risco a saúde do consumidor.

\section{AGRADECIMENTOS}

Ao CNPq e ao Fundo Estadual de Ciência e Tecnologia (FUNTEC) / Secretaria Executiva de Ciência, Tecnologia e Meio Ambiente (SECTAM), pelo apoio financeiro. A Dra. Eloísa Cardoso e aos assistentes Edson Sampaio e Solange Branches pela contribuição na execução deste trabalho.

\section{BIBLIOGRAFIA CITADA}

Brasil, Portaria n. 554, de 30 de agosto de 1995. 1995. Norma de identidade, qualidade, apresentaçáo, embalagem, armazenamento e transporte da farinha de mandioca. Diário Oficial da República Federativa do Brasil, Brasília, DF.

Borges, .M.F.; Fukuda, W.M.G.; Rossetti, A.G. 2002. Avaliação de variedades de mandioca para consumo humano. Pesquisa Agropecuária Brasileira, 37: 1559-1565.

Cagnon, J. R.; Cereda, M. P.; Pantarotto, S. 2002. Glicosídeos cianogênicos da cassava: biossíntese, distribuição, destoxificação e métodos de dosagem, p. 83-99. In: Cereda, M.P. (Coord.). Cultura de tuberosas amiláceas latino-americanas. Vol. 2. Fundação 
Cargill, São Paulo, São Paulo. (http://www.abam.com.br/ livroscargil/). Acesso: 24/03/2009.

Campbell-Platt, G. 1987. Fermented Foods of the World - a Dictionary and Guide. Butterworths \& Co. Ltd., London, 291pp.

Cardoso, E.M.R.; Müller, A. A.; Santos, A.I.M.; Homma, A.K.O.; Alves, R.N.B. 2001. Processamento e Comercializaçâo de Produtos Derivados de Mandioca no Nordeste Paraense. Série Documentos (n¹02). Embrapa Amazônia Oriental, Belém, Pará. 28pp.

Cereda, M.P;.2003. Processamento da mandioca como mecanismo de destoxificação, p. 47-80. In: Cereda, M.P. (Coord). Tecnologia, usos e potencialidades de tuberosas amiláceas Latino Americanas. Vol. 3. Fundação Cargill, São Paulo, São Paulo. (http://www. abam.com.br/livroscargil/). Acesso: 24/03/2009.

Cereda, M.P.; Lopes, A. M. 2003. In: Determinação do potencial de intoxicação em ratos, de linamarina extraída de mandioca. Vol. 1. Anais do V SLACA, Campinas, São Paulo.

Chisté, R.C.; Cohen, K.O.; Oliveira, S.S. 2007. Estudo das propriedades físico-químicas do tucupi. Ciência e Tecnologia de Alimentos, 27: 787-792.

Chisté, R.C.; Cohen, K.O. 2008. Determinação de cianeto total nas farinhas de mandioca do grupo seca e d'água comercializadas na cidade de Belém-PA. Revista Brasileira de Tecnologia Agroindustrial, 2: 96-102.

Cooke, R.D. 1978. An Enzymatic Assay for the Total Cyanide Content of Cassava (Manihot esculenta Crantz). Journal of the Science of Food and Agriculture, 29: 345-352.

Essers, A.J.A.; Bosveld, M.; Grift, R.M.V.; Voragen, A.G.J. 1993. Studies on the quantification of specific cyanogens in cassava products and introduction of a new chromogen. Journal of the Science of Food and Agriculture, 63: 287-296.

IBGE. 2007. Produção Agrícola Municipal: Culturas temporárias e permanentes, Rio de Janeiro, 34: 1-69. (http://www.ibge.gov. br). Acesso: 24/03/2009.
Lima, U. A. 1982. Manual técnico de beneficiamento e industrialização da mandioca. Sáo Paulo: Secretaria de Ciência e Tecnologia, 56 pp. (Programa Adequação).

Mattos, P.L.P. de; Gomes, J. de C.; Farias, A.R.N; Fukuda, C. 2002. Cultivo da mandioca nas regiôes norte e nordeste do Brasil, p. 274-301. In: Cereda, M.P. (Coord.). Cultura de tuberosas amiláceas latino-americanas. Vol. 2. Fundação Cargill, São Paulo, São Paulo. (http://www.abam.com.br/livroscargil/). Acesso: 24/03/2009.

Muzanila, Y.C; Brennan, J.G.; King, R.D. 2000. Residual cyanogens, chemical composition and aflatoxins in cassava flour from Tanzanian villages. Food Chemistry, 70: 45-49.

Onabowale, S.O. 1992. Constraints and projections for processing and utilization of cassava. In: Hahn, S.K.; Reynolds, L.; Egbunik, G.N. Cassava as livestock feed in Africa. Worshop on the potential utilization of cassava as livestock feed in Africa, Ibadan 1988. Proceedings: Ibadan, International Institut of Tropical Agricultura/ILCA/Universidade of Ibadan, p. 112-118. (http:// www.ilri.org/InfoServ/Webpub/Fulldocs/X5458e/x5458e0e. htm). Acesso: 24/03/2009.

Sarmiento, F. M. Z. 1993. Utilização de farinha de macaxeira (Manihot esculenta Crantz) obtida pelo método HEIM em panificação. Dissertação de Mestrado, Universidade Federal do Ceará, Fortaleza, Ceará. 71pp.

Unung, J.E.; Ajayi, O.A.; Bokanga, M. 2006. Effect of local processing methods on cyanogen content of cassava. Tropical Science, 46: 20-22.

Recebido em 24/03/2009

Aceito em 04/08/2009 